\title{
A New Type of Hypermethioninemia in Neonates
}

\author{
Akira Tsuchiyama, Kazuhiko Oyanagi, Fumiteru \\ Nakata, Noriyuki Uetsuji, Satoshi Tsugawa,* Tooru \\ NaKaO and Michio Mori $\dagger$ \\ Department of Pediatrics, Sapporo Medical College, Sapporo \\ 060, *Department of Pediatrics, Otaru National Hospital, \\ Otaru 047 and $\dagger$ Department of Pathology, Sapporo Medical \\ College, Sapporo 060
}

\begin{abstract}
Tsuchiyama, A., Oyanagi, K., Nakata, F., Uetsuji, N., Tsugawa, S., Nakao, T. and Mori, M. A New Type of Hypermethioninemia in Neonates. Tohoku J. exp. Med., 1982, 138 (3), 231-289 — Eleven hypermethioninemic patients were found by mass screening tests of neonates. Three of these had persistent hypermethioninemia while in the others it was transient. Serum concentrations of methionine were constantly higher than those of controls, especially in the persistent group. The enzyme activities of methionine adenosyltransferase in the liver tissues of both groups of patients were within normal limits. Serum concentrations of total folate in the persistent group were striking!y elevated and fatty degeneration of the liver tissues was a constant feature. It improved after several months under a low-methionine diet. The hypermethioninemia reported here is not associated with any clinical or biochemical finding reported previously. …...... hypermethioninemia; mass screening; fatty liver; methionine adenosyltransferase
\end{abstract}

Several disorders involving inborn errors of amino acid metabolism have been found by mass screening tests of neonates. The mass screening test for methionine was originally instituted to identify homocystinuria due to cystathionine $\beta$ synthase deficiency. Several inborn errors of metabolism of methionine, however, have since been reported in man (Mudd and Levy 1978).

Gaull and Tallan (1974) described methioninemia associated with a deficiency of hepatic methionine adenosyltransferase (MAT), and more recently, reported a new type of methioninemia which was associated with a proximal myopathy with normal activity of MAT in liver tissues (Gaull et al. 1981a).

We now report another type of methioninemia, which is not associated with any clinical or biochemical finding reported previously. Our persistent hypermethioninemic patients were asymptomatic recently, and MAT activity in liver tissues was normal. Histological findings of liver tissues, however, showed moderate fatty degeneration in all cases.

The purpose of the present study is to describe the clinical and biochemical findings observed in a new type of methioninemia.

Received for publication, February 15, 1982. 


\section{Case Reports}

The main clinical data of the patients are summarized in Table 1 . Cases 1 to 3 had persistent hypermethioninemia, while Cases 4 to 11 had transient hypermethioninemia. All patients were found by mass screening program of neonates.

Two patients, Cases 1 and 2 , were of the same pedigree, with the father of Case 1 and the mother of Case 2 being cousins (Fig. 1). All patients were the products of normal pregnancies and deliveries, and their neonatal periods were uneventful.

Beyond the age of three months serum concentrations of methionine in the patients were always higher than those of controls, but other serum amino acids were within normal limits. Neither homocystine nor cystathionine was detected in their urine specimens.

Routine peripheral blood analyses and urinalyses were within normal limits. Electroencephalograms and computed tomography of the brains of the patients revealed normal findings. Liver function tests of Case 3 indicated transient elevations of serum

TABLE 1. Clinical and biological data on patients with hypermethioninemia

\begin{tabular}{rccccccr} 
Cases & Sex & $\begin{array}{c}\text { Birth } \\
\text { weight }(\mathrm{g})\end{array}$ & $\begin{array}{c}\text { Serum } \\
\text { methionine } \\
(\mu \text { moles/liter })\end{array}$ & $\begin{array}{c}\text { Methionine } \\
\text { uptake } \\
(\mathrm{mg} / \mathrm{kg} / \mathrm{day})\end{array}$ & $\begin{array}{c}\text { Protein } \\
\text { intake } \\
(\mathrm{g} / \mathrm{kg} / \mathrm{day})\end{array}$ & Feeding & $\begin{array}{r}\text { Serum } \\
\text { folate } \\
(\mathrm{ng} / \mathrm{ml})\end{array}$ \\
\hline 1 & F & 3,155 & 228 & 60 & 3.0 & Breast & 160.0 \\
2 & F & 2,920 & 474 & 55 & 3.9 & Mixed & 243.0 \\
3 & M & 3,300 & 658 & 63 & 3.3 & Bottle & 1000.0 \\
4 & M & 3,100 & 94 & 60 & 3.3 & Mixed & 17.0 \\
5 & M & 3,340 & 94 & 63 & 3.1 & Mixed & 26.0 \\
6 & M & 2,850 & 87 & 82 & 3.3 & Bottle & 30.0 \\
7 & F & 3,300 & 100 & 97 & 3.6 & Bottle & Bottle \\
8 & M & 3,050 & 126 & 68 & 2.7 & Bottle & Bottle \\
9 & F & 3,240 & 114 & 80 & 3.2 & 3.6 & Bottle
\end{tabular}

Controls

$32.8 \pm 12.9$

Cases 1-3: Persistent hypermethioninemia.

Cases 4-11: Transient hypermethioninemia.

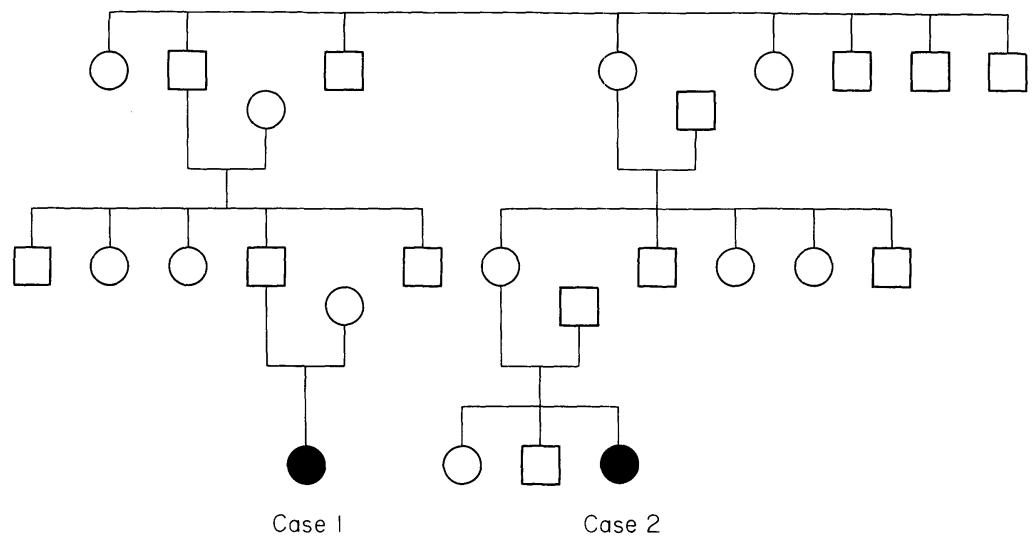

Fig. 1. Pedigree of a family with persistent hypermethioninemia. 

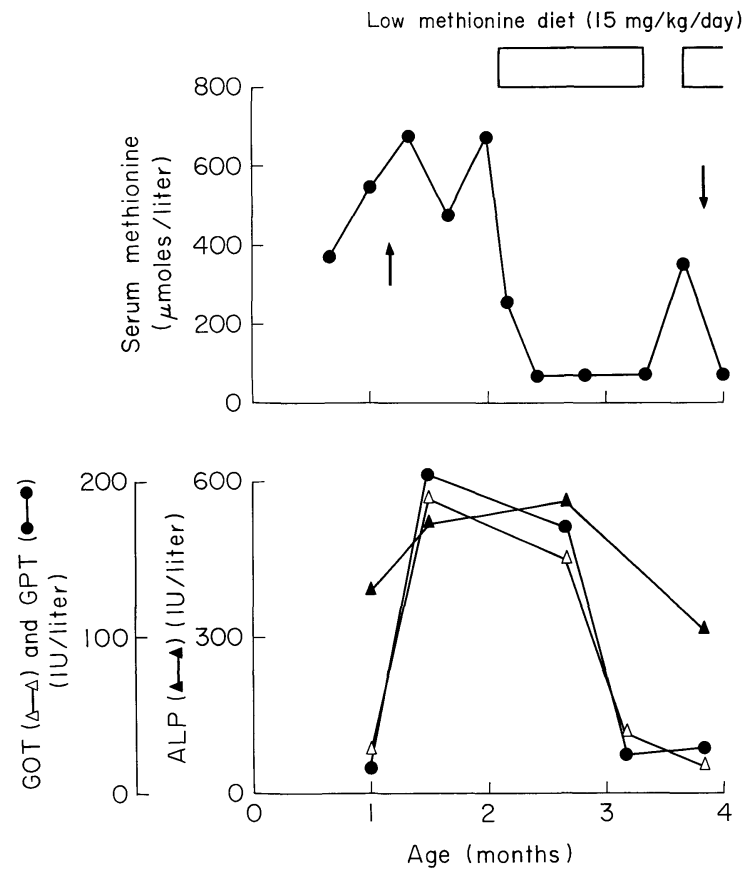

Fig. 2. Clinical course of Case 3, showing a transient elevation of serum glutamic oxaloacetic transaminase (GOT), glutamic pyruvic transaminase (GPT) and alkaline phosphatase (ALP). The arrows indicate liver biopsy.

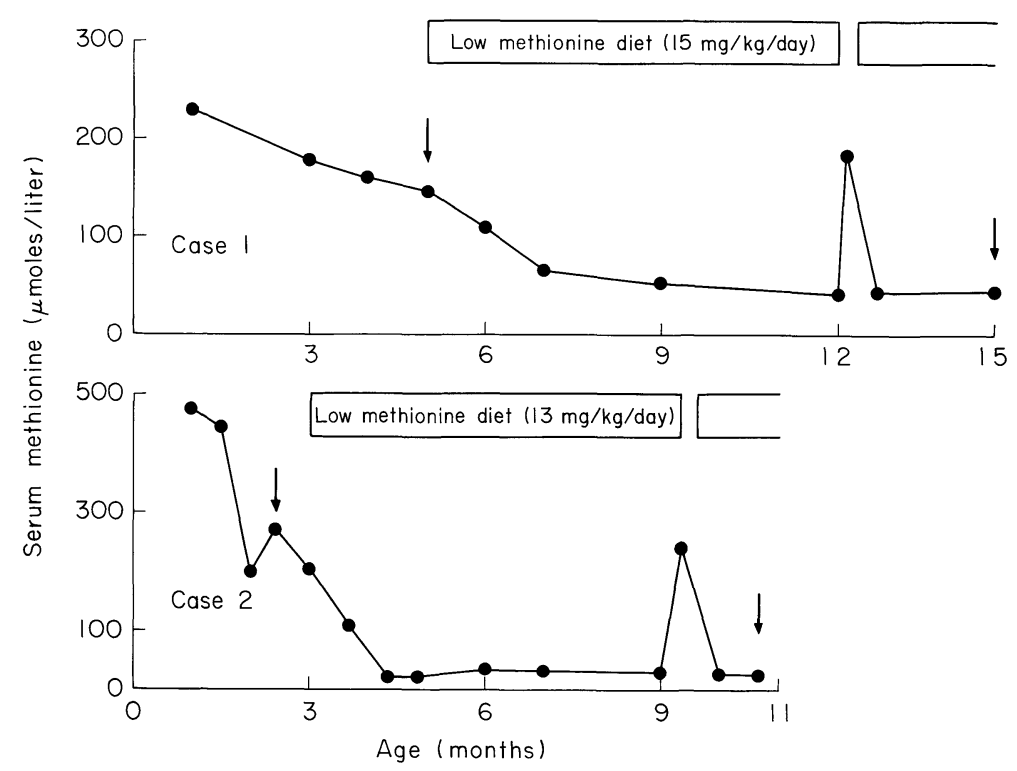

Fig. 3. Clinical course of two cases of persistent hypermethioninemia (Cases 1 and 2). The arrows indicate liver biopsy. 
glutamic pyruvic transaminase, glutamic oxaloacetic transaminase, and alkaline phosphatase in the presence of a high level of serum methionine (Fig 2).

One of the characteristic biochemical findings was that the serum concentrations of total folate were strikingly elevated in all patients with persistent hypermethioninemia.

On low-methionine diets $(15-20 \mathrm{mg} / \mathrm{kg} /$ day $)$, the serum levels of methionine of the persistent hypermethioninemic patients were rapidly decreased to the upper limits of the normal range. When the patients followed a normal diet for several days, however, the serum levels of methionine became elevated once again (Fig 3).

The persistent hypermethioninemic patients are well controlled under their lowmethionine diets, and have developed normally beyond infancy.

The serum concentrations of methionine of the eight infants with transient hypermethioninemia were lower than those of the persistent hypermethioninemic patients. Serum levels of methionine were decreased to the normal range on a normal diet within a matter of several months.

\section{Morphologic Study of Liver Tissue}

Histological examinations of liver tissues obtained by needle biopsy were performed in three cases of persistent hypermethioninemia and in four cases of transient hypermethioninemia. Light microscopic findings of the liver in the three persistent hypermethioninemic patients showed moderate fatty degeneration but no inflammatory or cirrhotic lesions were observed (Figs. 4, 5). The condition improved, however, following a low methionine diet.

Electron microscopic findings of liver tissues revealed no abnormality except for fat infiltrations. Histological findings of the liver tissues in the four transient hypermethioninemic patients also showed fatty degeneration, but to a lower degree

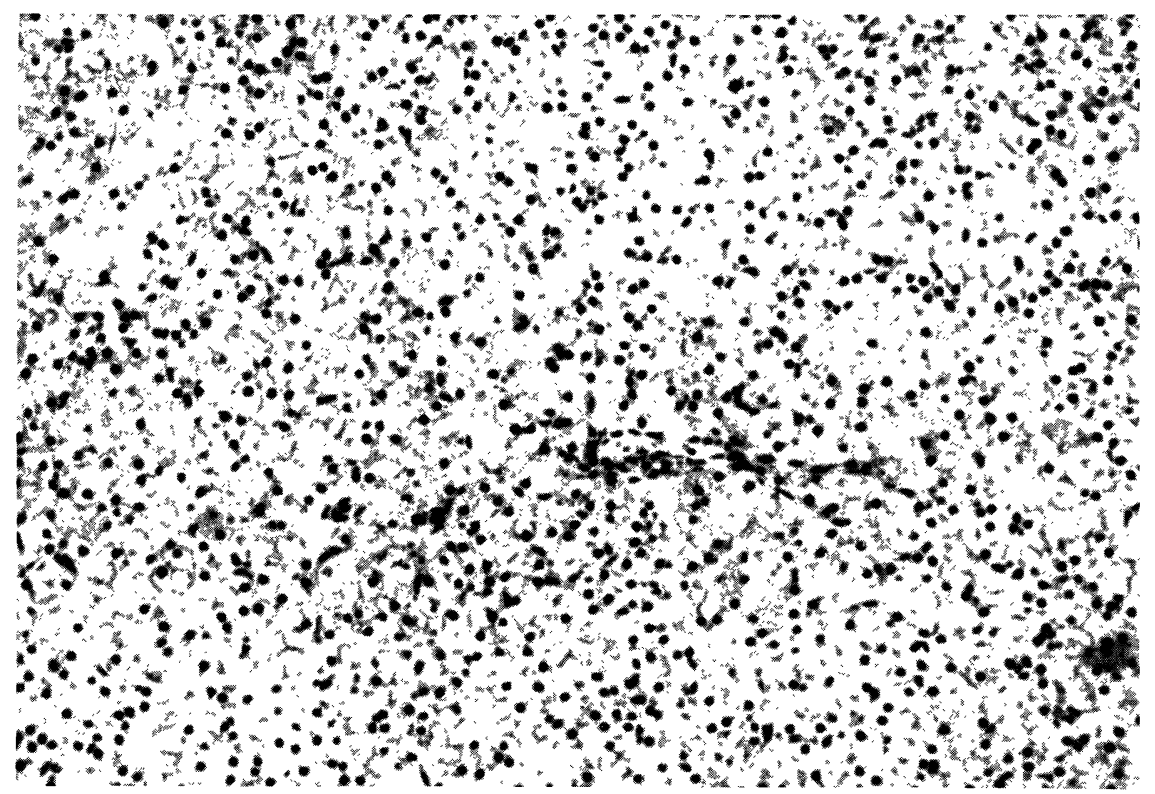

Fig. 4. Histological picture of biopsied liver tissue from Case 1, showing moderate fatty degeneration without inflammatory and cirrhotic lesions. Hematoxylin-eosin stain. 


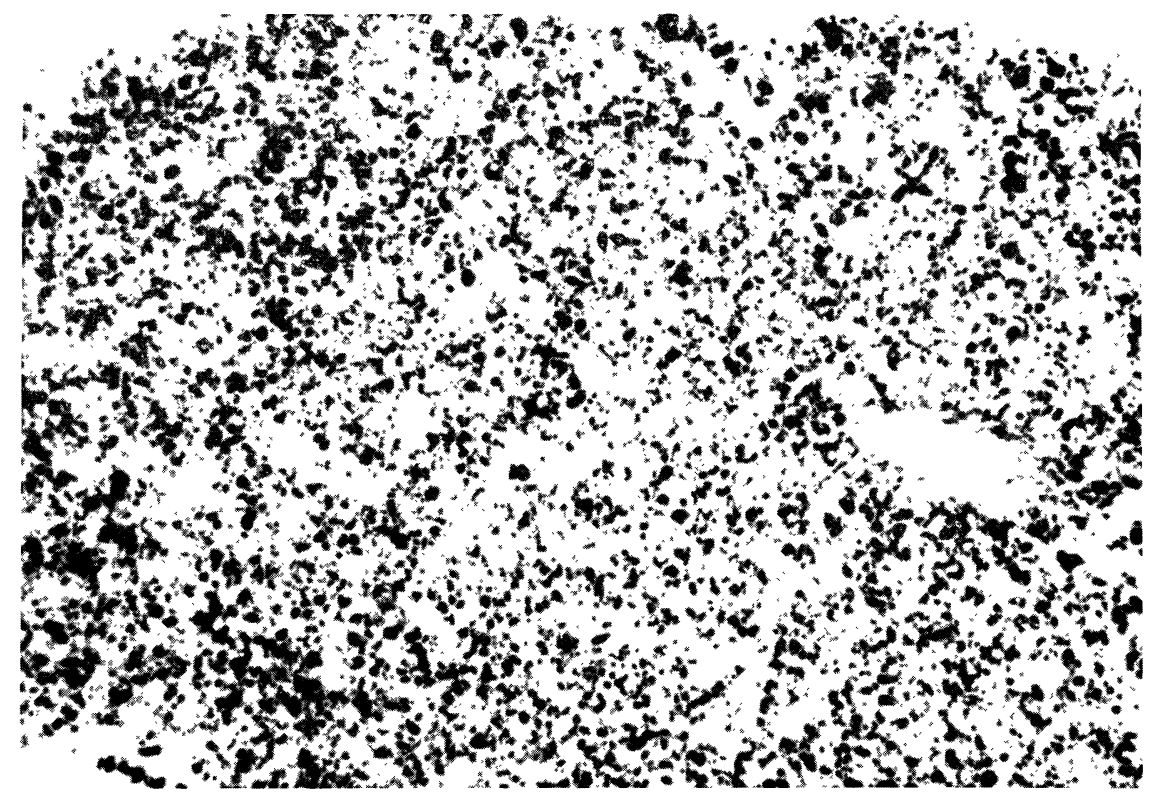

Fig. 5. Sudan stain of liver tissue from Case 1 before low methionine diet therapy, showing moderate fat droplets in hepatocytes.

than that of the persistent hypermethioninemic patients. These findings improved following the normalization of serum methionine levels.

\section{Study on Methionine Metabolism}

Quantitative analyses of amino acids in serum and urine were performed by means of an automatic amino acid analyzer (JCL-6AH type, JEOL Co.). The serum concentrations of methionine of the patients were constantly higher than those of controls, particularly in the persistent hypermethioninemic patients. Other amino acids, however, were within normal limits. Neither cystathionine nor homocystine was detected in any urine specimen and sodium cyanide nitroprusside tests in urine were also negative.

Oral loading tests of L-methionine were carried out in Cases 1 and 2, and in their parents. After overnight fasting, $100 \mathrm{mg}$ of L-methionine per $\mathrm{kg}$ of body weight was given orally and blood samples were taken before and 1,2, 4, and $6 \mathrm{hr}$ after the load. The results obtained are shown in Fig. 6. The serum concentrations of methionine of the patients after the load were apparently higher than those of controls, while those of parents showed a similar clearance curve to those of controls. The serum cystine levels of the patients after methionine load clearly increased as can be seen in Fig. 7.

Liver biopsies were performed with a Mengini needle. Specimens for histological studies and for the assay of enzyme activities were prepared. The liver tissues were stored at $-70^{\circ} \mathrm{C}$ until enzyme assays were performed. Methionine adenosyltransferase activities in the liver tissues were measured by the method of 
Mudd et al. (1965). The results obtained are shown in Table 2. The enzyme activities in the liver tissues of both groups of patients were within normal limits.

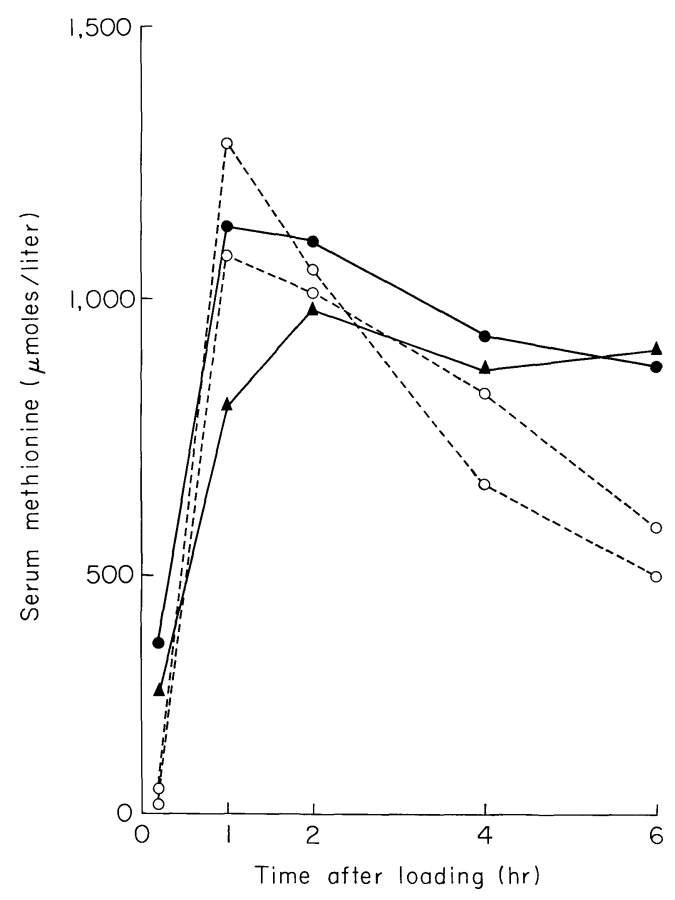

Fig. 6

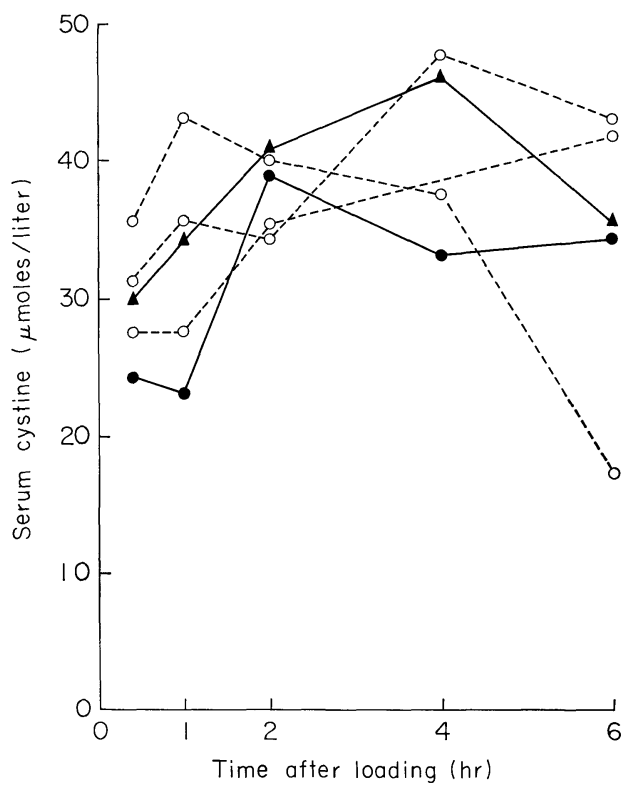

Fig. 7

Fig. 6. Oral loading tests of L-methionine $(100 \mathrm{mg} / \mathrm{kg})$. o-.-o, control.

Fig. 7. Oral loading tests of L-methionine $(100 \mathrm{mg} / \mathrm{kg})$. Serum cystine levels after loads.

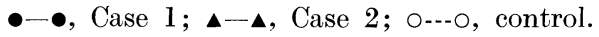

TABLE 2. Methionine adenosyltransferase activities in liver tissue

$$
\begin{gathered}
\text { MAT activity } \\
\text { (nmoles/mg protein/hr) }
\end{gathered}
$$

Persistent hypermethioninemic patients

$$
\text { Case } \begin{aligned}
& 1 \\
& 2 \\
& 3
\end{aligned}
$$

Transient hypermethioninemic patients

$$
\text { Case } \begin{array}{r}
\mathbf{4} \\
\mathbf{5}
\end{array}
$$

Controls

1
2
3
4

1. 12

1. 21

1. 72

1. 40

1. 39

0.95

1. 34

1. 89

1.09

1. 04 


\section{Disucssion}

The transsulfuration pathway of methionine is the chief route of disposal of methionine in man (Fig. 8) and several inborn errors of methionine metabolism have been reported, such as homocystinuria resulting from cystathionine $\beta$-synthase deficiency, hypermethioninemia with or without tyrosinemia, and severe generalized liver diseases (Mudd and Levy 1978). The most common cases of hypermethioninemia occur in neonates transiently, especially in premature infants (Gaull et al. 1977). Recently, cases of hypermethioninemia with hepatic MAT deficiency have been reported by several investigators (Gaull and Tallan 1974; Finkelstein et al. 1975; Gaull et al. 1981b). In 1981, Gaull et al. described a new type of hypermethioninemia which was associated with a proximal myopathy and in which MAT was not deficient. Gaull et al. proposed that there were at least three different types of specific methioninemia: type I, methioninemia associated with hepatic MAT deficiency; type II, methioninemia without hepatic MAT deficiency but associated with myopathy; type III, methioninemia associated with neither MAT deficiency nor myopathy.

Our persistent hypermethioninemic patients were clinically similar to the type III methioninemia proposed by Gaull et al., but the histological findings of

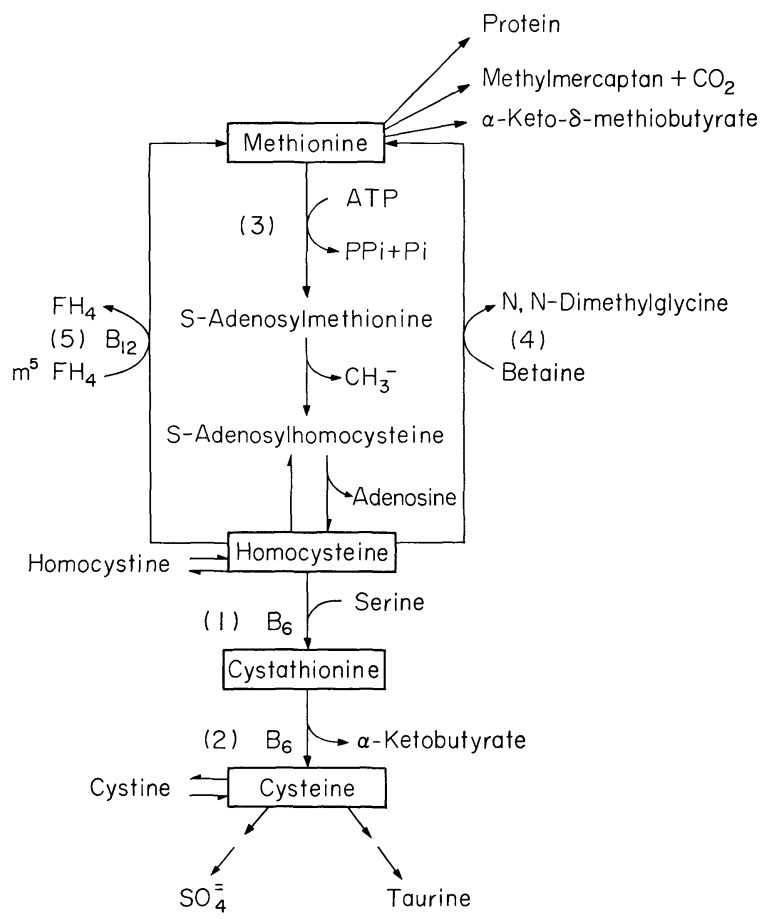

Fig. 8. Transsulfuration and remethylation pathways. (1) cystathionine $\beta$-synthase; (2) cystathionase; (3) methionine adenosyl-transferase; (4) betaine-homocystine methyltransferase; (5) $\mathrm{N}^{5}$-methyltetrahydrofolate-homocystine methyltransferase; $\mathrm{FH}_{4}$, tetrahydrofolate; $\mathrm{m}^{5} \mathrm{FH}_{4}, \mathrm{~N}^{5}$-methyltetrahydrofolate. 
liver tissues are apparently different from any other type of methioninemia reported previously.

The mechanism of the hypermethioninemia of our patients is still unknown. Serum concentrations of cystine were clearly increased after an oral load of methionine and cystathionine and homocystine were always negative in urine specimens. This indicated that the transsulfuration pathway should be operative. From the results of the abnormal clearance pattern in serum methionine after the load and normal hepatic MAT activities, it is speculated that the cause of hypermethioninemia may be a defect in some other methionine degradation pathway than the transsulfuration pathway.

The high serum concentrations of total folate in the persistent hypermethioninemic patients suggest that the activity of $\mathrm{N}^{5}$ methyltetrahydrofolatehomocystine methyltransferase may be inhibited because of negative feedback due to the accumulation of methionine (Gaull and Tallan 1974).

Two persistent hypermethioninemic patients from the consanguineous marriage reported here were found to have the same pedigree, and the mode of inheritance seems to have been autosomal recessive.

The question arises as to whether or not to treat this condition. Moderate fatty degeneration of the liver tissues of our patients was a constant feature, but improved under low-methionine diet after several months, resulting in no mental or physical retardation. Therefore we consider that this metabolic inherited disorder should be treated.

\section{References}

1) Finkelstein, J.D., Kyle, W.E. \& Martin, J.J. (1975) Abnormal methionine adenosyltransferase in hypermethioninemia. Biochem. biophys. Res. Commun., 66, 1491-1497.

2) Gaull, G.E. \& Tallan, H.H. (1974) Methionine adenosyltransferase deficiency: New enzymatic defect associated with hypermethioninemia. Science, 186, 59-60.

3) Gaull, G.E., Rassin, D.K., Räihä, N.C.R. \& Heinonen, K. (1977) Milk protein quantity and quality in low-birth-weight infants. III. Effects on sulfur amino acids in plasma and urine. J. Pediatr., 90, 348-355.

4) Gaull, G.E., Bender, A.N., Vulovic, D., Tallan, H.H. \& Schaffner, F. (1981a) Methioninemia and myopathy: A new disorder. Ann. Neurol., 9, 423-432.

5) Gaull, G.E., Tallan, H.H., Lonsdale, D., Przyrembel, H., Schaffner, F. \& von Bassewitz, D.B. (1981b) Hypermethioninemia associated with methionine adenosyltransferase deficiency: Clinical, morphologic, and biochemical observations on four patients. J. Pediatr., 98, 734-741.

6) Mudd, S.H. \& Levy, H.L. (1978) Disorders of transsulfuration. In: The Metabolic Basis of Inherited Disease, edited by J.B. Stanbury, J.B. Wyngaarden, \& D.S. Fredrickson, McGraw-Hill Book Company, New York, pp. 458-503.

7) Mudd, S.H., Finkelstein, J.D., Irreverre, F. \& Laster, L. (1965) Transsulfuration in mammals, microassay and tissue distributions of three enzymes of the pathway. $J$. biol. Chem., 240, 4382-4392. 